\title{
Nitrate and nitrite in commercial samples of conventional, organic and hydroponic leafy vegetables
}

\author{
Ana Luiza do Nascimento, Luciano Valdemiro Gonzaga, Fabiana Della Betta, Mayara Schulz*, \\ Fabíola Carina Biluca, Siluana Katia Tischer Seraglio, Ana Carolina Oliveira Costa, Roseane Fett*
}

Department of Food Science and Technology, Federal University of Santa Catarina, 88034-001, Florianopolis, SC, Brazil

\section{A B S T R A C T}

\begin{abstract}
The aim of this research was to investigate along four weeks the nitrate and nitrite levels in commercial samples of leafy vegetables (lettuce, watercress, spinach, and rocket) of different growing systems (hydroponic, conventional and organic) using a capillary electrophoresis method. In all samples, nitrite content was below the limit of detection, while nitrate was quantified. The nitrate concentrations in the leafy vegetables ranged from 239.26 to $7873.00 \mathrm{mg} \mathrm{kg}^{-1}$ in fresh weight, with more expressive values found for lettuce, watercress and rocket in the hydroponic system, while for spinach the highest values were found in the conventional system. However, the lettuce can be highlighted as the vegetable with the lowest content of nitrate and the rocket the vegetable with the highest content of this compound. Despite the great variability, the nitrate levels found for most samples were in accordance with international requirements.
\end{abstract}

Keywords: Cultivation system; Lettuce; Rocket; Spinach; Watercress

\section{INTRODUCTION}

During the plant growth and development, nitrate $\left(\mathrm{NO}_{3}^{-}\right)$ is one of the most abundant and important sources of nitrogen, independent of the growing system (CardenasNavarro et al., 1999; Iammarino et al., 2013). In plants, nitrate concentration depends of its absorption and assimilation. Nitrate is absorbed in the root and its excess is accumulated in storage organs (Bóbics et al., 2016). Therefore, large amounts of nitrate in plants, especially in leafy vegetables, are commonly observed (Alexander et al., 2008; Bian et al., 2018; Cardenas-Navarro et al., 1999; Iammarino et al., 2013).

The consumption of vegetables as sources of phytochemicals in the human diet has been related with health-promoting properties (Bian et al., 2018; Chan, 2011). However, as most of leafy vegetables have a great ability to accumulate nitrate especially in its leaves, they are the main contributors in human intake of this compound (Alexander et al., 2008; Bian et al., 2018; Bóbics et al., 2016; Weitzberg and Lundberg, 2013). It is estimated that 60 to $80 \%$ of the daily human consumption of nitrate are from vegetables (Suresh et al., 2018; Weitzberg and Lundberg, 2013). Nitrate levels in vegetables usually higher than $700 \mathrm{mg} \mathrm{kg}^{-1}$ can result in the increasing of harmful effects on human health (BruningFann and Kaneene, 1993), such as methemoglobinemia and cancers (Alexander et al., 2008; Chan, 2011; Santamaria, 2006; Suresh et al., 2018; Weitzberg and Lundberg, 2013). The human toxicity and carcinogenicity of nitrate is due to its enzymatic conversion to nitrite $\left(\mathrm{NO}_{2}^{-}\right)$in the body, a toxic compound (Lei et al., 2018; Suresh et al., 2018; Weitzberg and Lundberg, 2013). However, recent researches have also suggested useful or not damage effects related to the intake of nitrate (Habermeyer et al., 2015; Jonvik et al., 2016). Despite this, due to the risk of excessive intake of nitrate/ nitrite, the Scientific Committee on Food and the Joint Food and Agriculture Organization/World Health Organization Expert Committee on Food Additives have established as Acceptable Daily Intake (ADI) for nitrate of $222 \mathrm{mg}$ nitrate/ day for a $60 \mathrm{~kg}$ adult, equivalent to $3.7 \mathrm{mg}$ per $\mathrm{kg}$ body weight (World Healthy Organization, 2003). Additionally, permissible limits has been set for some leafy vegetables for European countries (European Commission, 2011).

Nitrate is widely used in greenhouses for vegetable production, especially in hydroponic growing system

\footnotetext{
${ }^{*}$ Corresponding author:

Mayara Schulz and Roseane Fett, Department of Food Science and Technology, Federal University of Santa Catarina, Rodovia Admar Gonzaga, 1346, Itacorubi, CEP: 88034-001, Florianopolis, SC, Brazil. Phone: +55 48 37215374. E-mail: schulzmay@gmail.com and roseane.fett@gmail.com 
(Cardenas-Navarro et al., 1999; Lei et al., 2018). However, the use and the management of nitrogen fertilizers in conventional growing system in order to improving the crop productivity also contributes to nitrate accumulation in plants (Chan, 2011; Haftbaradaran et al., 2018; Iammarino et al., 2013). Additionally, nitrate accumulation by plants is also largely influenced by biological, edaphoclimatic, and agricultural factors (such as plant cultivar, variety, light intensity, soil, temperature, and nutritional composition), as well as by storage and/or processing methods (such as storage temperature) (Alexander et al., 2008; Bian et al., 2018; Bóbics et al., 2016; Cardenas-Navarro et al., 1999; Chan, 2011; Ekart et al., 2013; Suresh et al., 2018).

Investigations carried out with vegetables has shown low levels of nitrite, but high nitrate concentrations, especially in leafy vegetables, such as Iranian vegetables (lettuce, basil, parsley, coriander, cress, dill, fenugreek, leek, mint, tarragon, spinach, and others) (Bahadoran et al., 2016), Mediterranean fresh salad vegetables (head cabbage, cellery leaves, coriander, dill, chards, purslane, parsley, rucola, and spinach (Kyriacou et al., 2019), Turkey lettuce (Aydinsakir et al., 2019), and Cyprus lettuce, spinach, rucola, purslane, and beet leaves (Stavroulakis et al., 2018). In many cases the levels found were above the recommended limits, reinforcing the importance of monitoring nitrate levels in leafy vegetables to protect consumer health.

In this context, the aim of this study was to investigate along four weeks the nitrate and nitrite levels in commercial samples of lettuce (Lactuca sativa L.), watercress (Nasturtium officinale), spinach (Spinacea oleracea L.), and rocket (Eruca sativa Mill) cultivated in hydroponic, organic, and conventional systems.

\section{MATERIALS AND METHODS}

\section{Reagents and solutions}

All standard solutions were prepared using analytical grade reagents and deionized water (Milli-Q, Millipore, Bedford, MA, USA). Sodium nitrate, sodium nitrite, potassium thiocyanate (Internal Standard - I.S.), perchloric acid $(70 \%), \beta$-alanine were purchased from Sigma-Aldrich (St. Louis, CO, USA). Sodium hydroxide was purchased from Synth (Diadema, SP, Brazil). Standard solutions of the analytes and the I.S. (1000 $\left.\mathrm{mg} \mathrm{L}^{-1}\right)$, and stock solutions of background electrolyte (BGE) components (100 mmol $\mathrm{L}^{-1}$ ) were prepared and stored at $4 \pm 2{ }^{\circ} \mathrm{C}$ until analysis when they were diluted to obtain the working concentration.

\section{Samples and sample preparation}

Samples of lettuce (Lactuca sativa L.), watercress (Nasturtium officinale), spinach (Spinacea oleracea L.), and rocket (Eruca sativa Mill) cultivated by hydroponic, conventional and organic systems were obtained in the local market of Florianopolis (Santa Catarina, Brazil) in the months of July to August of 2017. Three samples of each vegetable cultivated in the three growing systems were collected weekly, along four weeks. Is noteworthy to mention that all the samples were obtained from the same producer and the same place of cultivation.

After the collection, the samples were washed with potable water, deionized water, and drained. Then, the leafy vegetable was packaged in paper bags and dried at an air forced oven by $12 \mathrm{~h}$ at $75 \pm 2{ }^{\circ} \mathrm{C}$ (FANEN, Fabbe 170, Sao Paulo, SP, Brazil). After dried, the samples were triturated with a mill (IKA-A11, Rio de Janeiro, RJ, Brazil) and stored in polyethylene tubes until the analysis. The moisture content of the in natura leafy vegetables was determined according to the AOAC reference method 925.09 (AOAC, 2005).

The sample preparation was carried out by weighing (Mettler Toledo, AB204-S, Zürich, Switzerland) into polyethylene tubes $100 \pm 1 \mathrm{mg}$ of the dried sample. An aliquot of $10 \mathrm{~mL}$ of deionized water at $60^{\circ} \mathrm{C}$ was added to each tube, which was sealed, stirred in a vortex for $1 \mathrm{~min}$, and cooled to room temperature. Following, the samples were transferred to microtubes and centrifuged for $8 \mathrm{~min}$ at $14000 \mathrm{rpm}$ (MiniSpin plus, Eppendorf, Hamburg, Germany). The supernatant was collected and diluted with the I.S (final concentration of $25 \mathrm{mg} \mathrm{L}^{-1}$ ). At a proportion of $1: 1(\mathrm{v} / \mathrm{v})$ and injected at the capillary electrophoresis system. For samples with high nitrate concentration, the supernatants were diluted with deionized water previously to the dilution with the I.S. All determinations were performed in triplicate of preparation and injection.

\section{Determination of nitrate and nitrite by CE-DAD}

The determination of nitrate and nitrite in leafy vegetables was performed using the method previously described by Della Betta et al. (2014). The results were expressed in $\mathrm{mg} \mathrm{kg}^{-1}$ in fresh weight (FW)

\section{Statistical analysis}

All the quantification data were expressed as a mean \pm standard deviation and analyzed using Statistica 13.0 software (Statsoft Inc., Tulsa, OK, USA). The mean values of each leafy vegetable were submitted to analysis of variance (ANOVA) and the Tukey test was carried out to identify significant differences $(p<0.05)$.

\section{RESULTS AND DISCUSSION}

In all leafy vegetable investigated, the nitrite concentration was below the limit of detection of the method $\left(0.15 \mathrm{mg} \mathrm{L}^{-1}\right)$, while nitrate was quantified in all samples (Table 1). In a 
Table 1: Nitrate content ( $\mathrm{mg} \mathrm{kg}^{-1}$ in fresh weight) in lettuce, watercress, spinach and rocket grown in hydroponic, organic and conventional systems obtained from four collections

\begin{tabular}{|c|c|c|c|c|}
\hline Crop species & Growing system & Collection period (week) & Nitrite & Nitrate \\
\hline \multirow[t]{12}{*}{ Lettuce } & Hydroponic & 1 & $<\mathrm{LOD}$ & $1531.26 \pm 12.79^{\text {d.A }}$ \\
\hline & & 2 & $<$ LOD & $963.134 \pm 40.30^{\text {b.B }}$ \\
\hline & & 3 & $<$ LOD & $505.25 \pm 5.87^{\mathrm{a} . \mathrm{A}}$ \\
\hline & & 4 & $<\mathrm{LOD}$ & $1111.38 \pm 28.50^{\text {c.A }}$ \\
\hline & Organic & 1 & $<\mathrm{LOD}$ & $939.47 \pm 1.45^{\mathrm{b} . \mathrm{B}}$ \\
\hline & & 2 & $<\mathrm{LOD}$ & $1230.57 \pm 28.65^{\text {d.A }}$ \\
\hline & & 3 & $<$ LOD & $137.31 \pm 4.69^{\mathrm{a} . \mathrm{c}}$ \\
\hline & & 4 & $<\mathrm{LOD}$ & $1089.33 \pm 39.70^{\mathrm{c} . A}$ \\
\hline & Conventional & 1 & $<\mathrm{LOD}$ & $1513.55 \pm 74.66^{\text {c.A }}$ \\
\hline & & 2 & $<$ LOD & $1227.22 \pm 5.12^{\mathrm{b} . \mathrm{A}}$ \\
\hline & & 3 & $<$ LOD & $291.12 \pm 5.66^{а . в}$ \\
\hline & & 4 & $<$ LOD & $239.26 \pm 5.83^{\text {a.в }}$ \\
\hline \multirow[t]{12}{*}{ Watercress } & Hydroponic & 1 & $<\mathrm{LOD}$ & $3732.34 \pm 8.044^{\text {a.c }}$ \\
\hline & & 2 & $<$ LOD & $6036.63 \pm 137.26^{c . c}$ \\
\hline & & 3 & $<\mathrm{LOD}$ & $5598.38 \pm 109.69^{b . c}$ \\
\hline & & 4 & $<$ LOD & $3629.11 \pm 115.48^{\mathrm{a} . \mathrm{C}}$ \\
\hline & Organic & 1 & $<\mathrm{LOD}$ & $1625.48 \pm 70.91^{\mathrm{b} . \mathrm{B}}$ \\
\hline & & 2 & $<$ LOD & $895.25 \pm 38.87^{\mathrm{a} . \mathrm{A}}$ \\
\hline & & 3 & $<$ LOD & $887.18 \pm 39.62^{\mathrm{a} . \mathrm{A}}$ \\
\hline & & 4 & $<$ LOD & $2407.64 \pm 61.43^{\text {c.A }}$ \\
\hline & Conventional & 1 & $<\mathrm{LOD}$ & $1252.91 \pm 25.10^{\mathrm{a} . \mathrm{A}}$ \\
\hline & & 2 & $<\mathrm{LOD}$ & $1858.03 \pm 72.89^{\mathrm{d} . \mathrm{B}}$ \\
\hline & & 3 & $<$ LOD & $1613.72 \pm 58.46^{\mathrm{c} . \mathrm{B}}$ \\
\hline & & 4 & $<\mathrm{LOD}$ & $1457.79 \pm 23.67^{\text {b.B }}$ \\
\hline \multirow[t]{12}{*}{ Spinach } & Hydroponic & 1 & $<$ LOD & $3368.29 \pm 88.45^{\mathrm{d} . \mathrm{B}}$ \\
\hline & & 2 & $<\mathrm{LOD}$ & $1298.56 \pm 50.57^{\text {b. B }}$ \\
\hline & & 3 & $<$ LOD & $766.71 \pm 28.13^{\mathrm{a} . \mathrm{B}}$ \\
\hline & & 4 & $<\mathrm{LOD}$ & $2034.49 \pm 94.12^{\mathrm{c} . \mathrm{A}}$ \\
\hline & Organic & 1 & $<\mathrm{LOD}$ & $2892.77 \pm 125.92^{\text {d.A }}$ \\
\hline & & 2 & $<\mathrm{LOD}$ & $589.28 \pm 18.88^{\text {b.A }}$ \\
\hline & & 3 & $<\mathrm{LOD}$ & $277.44 \pm 12.63^{\mathrm{a} . \mathrm{A}}$ \\
\hline & & 4 & $<$ LOD & $1979.42 \pm 5.77^{\mathrm{C} . \mathrm{A}}$ \\
\hline & Conventional & 1 & $<\mathrm{LOD}$ & $4014.18 \pm 10.71^{\text {d.c }}$ \\
\hline & & 2 & $<\mathrm{LOD}$ & $3580.84 \pm 57.84^{c . c}$ \\
\hline & & 3 & $<\mathrm{LOD}$ & $1142.48 \pm 39.48^{\text {a.c }}$ \\
\hline & & 4 & $<$ LOD & $3071.06 \pm 137.54^{\text {b.c }}$ \\
\hline \multirow[t]{12}{*}{ Rocket } & Hydroponic & 1 & $<\mathrm{LOD}$ & $7873.00 \pm 236.94^{c . B}$ \\
\hline & & 2 & $<\mathrm{LOD}$ & $5571.32 \pm 173.37^{\text {a.A }}$ \\
\hline & & 3 & $<\mathrm{LOD}$ & $4127.43 \pm 124.46^{\text {b.B }}$ \\
\hline & & 4 & $<\mathrm{LOD}$ & $5446.69 \pm 67.82^{a . B}$ \\
\hline & Organic & 1 & $<$ LOD & $6391.49 \pm 243.59^{\text {d.A }}$ \\
\hline & & 2 & $<\mathrm{LOD}$ & $5659.52 \pm 134.55^{\text {c.A }}$ \\
\hline & & 3 & $<$ LOD & $5068.14 \pm 66.84^{\text {b.A }}$ \\
\hline & & 4 & $<\mathrm{LOD}$ & $4546.59 \pm 8.62^{\mathrm{a} . \mathrm{A}}$ \\
\hline & Conventional & 1 & $<$ LOD & $6424.34 \pm 255.15^{\text {c.A }}$ \\
\hline & & 2 & $<\mathrm{LOD}$ & $6099.26 \pm 200.41^{\text {b.c. }}$ \\
\hline & & 3 & $<\mathrm{LOD}$ & $5360.05 \pm 205.78^{\mathrm{a} . A}$ \\
\hline & & 4 & $<\mathrm{LOD}$ & $5848.51 \pm 164.07^{\text {a.b.c }}$ \\
\hline
\end{tabular}

Values expressed as mean \pm standard deviation. ${ }^{\mathrm{a}-\mathrm{d}}$ Different lowercase letters in the same growing system indicate significant differences between the means (Tukey, $P<0.05$ ). ${ }^{A-C}$ Different uppercase letters in the same collection period indicate significant differences between means (Tukey, $\left.P<0.05\right)$. LOD: Limit of detection. LOD nitrite: $0.15 \mathrm{mg} \mathrm{L}^{-1}$

general way, it is possible to observe that nitrate presented more expressive values in the hydroponic system for lettuce, watercress and rocket. However, for spinach the highest values were found in the conventional system.
The concentrations of nitrate in the hydroponic lettuce samples ranged from 505.25 to $1531.26 \mathrm{mg} \mathrm{kg}^{-1} \mathrm{FW}$, forsamples from the organic system from 137.31 to $1230.57 \mathrm{mg} \mathrm{kg}^{-1} \mathrm{FW}$ and for samples produced under conventional system from 
239.26 to $1513.55 \mathrm{mg} \mathrm{kg}^{-1} \mathrm{FW}$ (Table 1). These values are within the legal limits recommended by European Union regulations, which determines a maximum content of 4000 to $4500 \mathrm{mg} \mathrm{kg}^{-1} \mathrm{FW}$ for lettuces harvested in the autumn/ winter and 2500 to $3500 \mathrm{mg} \mathrm{kg}^{-1} \mathrm{FW}$ for those harvested between spring/summer period (European Commission, 2011).

Favaro-Trindade et al. (2007) found values of nitrate higher than the present study and also observed that the nitrate content in organic lettuce (565.4 $\mathrm{mg} \mathrm{kg}^{-1} \mathrm{FW}$ ) was significantly lower than those determined in the conventional (2782.1 $\mathrm{mg} \mathrm{kg}^{-1} \mathrm{FW}$ ) and hydroponic (3093.4 $\mathrm{mg} \mathrm{kg}^{-1} \mathrm{FW}$ ) systems. Lima et al. (2008) also found higher values of nitrate for hydroponic lettuces, followed by the conventional system and, finally, the organic system. In contrast, the values found by these authors were lower than the present study, since those samples were collected during the summer (high luminosity period), where nitrate accumulation is generally lower.

In relation to watercress, the samples produced by the hydroponic system showed the highest concentrations of nitrate ( 3629.11 to $6036.63 \mathrm{mg} \mathrm{kg}^{-1} \mathrm{FW}$ ), followed by organic (887.18 to $2407.64 \mathrm{mg} \mathrm{kg}^{-1} \mathrm{FW}$ ) and conventional (1252.91 to $1858.03 \mathrm{mg} \mathrm{kg}^{-1} \mathrm{FW}$ ) systems (Table 1). There is no legislation for nitrate content for watercress, however, other authors have also found high values of nitrate in this vegetable cultivated in hydroponic (2009 to $6160 \mathrm{mg} \mathrm{kg}^{-1} \mathrm{FW}$ ), organic (3340 to $5926 \mathrm{mg} \mathrm{kg}^{-1} \mathrm{FW}$ ) and conventional (296 to $2388 \mathrm{mg} \mathrm{kg}^{-1} \mathrm{FW}$ ) systems (Guadagnin et al., 2005).

The nitrate concentrations in the spinach samples evaluated varied from 766.71 to $3368.29 \mathrm{mg} \mathrm{kg}^{-1} \mathrm{FW}$ for hydroponic system, from 277.44 to $2892.77 \mathrm{mg} \mathrm{kg}^{-1} \mathrm{FW}$ for the organic system and from 1142.48 to $4014.18 \mathrm{mg} \mathrm{kg}^{-1} \mathrm{FW}$ in conventional system (Table 1). Samples of the conventional and hydroponic spinach plants analyzed were above the stipulated limit by European Union (3000 mg kg-1 FW), whereas the organic spinach plants presented contents according to the regulation. A study by Kreutz et al. (2012) reported values from 1441.5 to $2141.2 \mathrm{mg} \mathrm{kg}^{-1} \mathrm{FW}$ for spinach grown in the conventional system and from 1150.3 to $1771.3 \mathrm{mg} \mathrm{kg}^{-1} \mathrm{FW}$ for organic spinach samples. Nitrate levels lower than the present study were also found by Stertz et al. (2004), which reported values of up to $311.01 \mathrm{mg} \mathrm{kg}^{-1} \mathrm{FW}$ for spinach in the conventional system and up to $614.96 \mathrm{mg} \mathrm{kg}^{-1} \mathrm{FW}$ for organic spinach. As described for lettuce, these lower levels of nitrate for spinach described by other authors may be related to the fact that the samples analyzed by them were collected in the summer.

Lastly, nitrate levels in the rocket samples ranged from 4127.43 to $7873.00 \mathrm{mg} \mathrm{kg}^{-1} \mathrm{FW}$ for the hydroponic system, from 6391.49 to $4546.59 \mathrm{mg} \mathrm{kg}^{-1} \mathrm{FW}$ in the organic system and from 6424.34 to $5360.05 \mathrm{mg} \mathrm{kg}^{-1} \mathrm{FW}$ in the conventional system (Table 1). For rocket, the stipulated limit by European Union is $7000 \mathrm{mg} \mathrm{kg}^{-1} \mathrm{FW}$ for plants cultivated in the winter. In this way, only one sample of hydroponic rocket do not comply with this regulation. High nitrate values in hydroponically cultivated rocket (6461 to $9760 \mathrm{mg} \mathrm{kg}^{-1} \mathrm{FW}$ ) were also reported by Guadagnin et al. (2005). As in the present study, nitrate levels in rocket cultivated in the hydroponic system were followed by the samples grown in conventional and organic systems.

The nitrate contents found for the four leafy vegetables evaluated are in accordance with the classification described by Colla et al. (2018), which describes the nitrate content in lettuce as medium, high in spinach, very high in watercress and extremely high in rocket. The differences in nitrate levels found among the different evaluated vegetables may be related to the different absorption and transportation degrees in each plant (Guadagnin et al., 2005). In addition, the significant variations between the collections and between the growing systems for the same vegetable confirm that different factors can affect the concentration of nitrate in the plants, since the leafy vegetables have different behaviors compared to the factors exposed to them, such as $\mathrm{pH}$, incidence of sunlight, type of fertilization, harvest time, soil composition, among others (Correia et al., 2010).

Regarding the growing system, the highest concentrations of nitrate observed for most samples of the hydroponic system is related to its availability in the system, since the nitrate is totally free, allowing the complete absorption of the nutrient solution and, consequently, greater accumulation in hydroponic vegetables compared to those grown in other systems (Colla et al., 2018; Stertz et al., 2004). The vegetables grown in the conventional growing system also tend to present higher values of nitrate in relation to the organic system, because it makes use of chemical fertilizers of medium and high solubility and concentration (Stertz et al., 2004). The organic system usually presents lower values of nitrate due to the use of organic fertilizers that contain the nutrients in the form of nitrogen salts and organic compounds, thus contributing to a lower accumulation of nitrate (Colla et al., 2018; Guadagnin et al., 2005).

\section{CONCLUSIONS}

This study demonstrated that the lettuce can be highlighted as the vegetable with the lowest content of nitrate, while the rocket showed the highest concentration of this compound. The higher concentrations of nitrate 
were observed for the leafy vegetables growing in the hydroponic system when compared to those growing in conventional and organic systems. In addition, the nitrate content presented a great variation among the $r$ collections performed, suggesting the influence of edaphoclimatic and agricultural factors. Despite the great variability, the nitrate levels found for most samples are in accordance with international requirements.

\section{ACKNOWLEDGMENTS}

This study was financed in part by the Coordenação de Aperfeiçoamento de Pessoal de Nível Superior - Brasil (CAPES) - Finance Code 001. The authors also wish to thank the Conselho Nacional de Desenvolvimento Científico e Tecnológico (CNPq) and Fundação de Amparo à Pesquisa do Estado de Santa Catarina (FAPESC) for the fellowships and financial support.

\section{Author's contributions}

In this research, all authors contributed effectively. Ana Luiza do Nascimento, Fabiana Della Betta, and Luciano Valdemiro Gonzaga designed and achieved experiments, and analysed the data; Ana Luiza do Nascimento, Fabiana Della Betta, Mayara Schulz, Fabíola Carina Biluca, Siluana Katia Tischer Seraglio performed data interpretation and wrote the paper; Luciano Valdemiro Gonzaga, Ana Carolina Oliveira Costa, and Roseane Fett supervised the project and revised the manuscript.

\section{REFERENCES}

Alexander, J., D. Benford, A. Cockburn, J. Cravedi, E. Dogliotti, A. Di Domenico, M. L. Fernández-Cruz, J. Fink-Gremmels, P. Fürst, C. Galli, P. Grandjean, J. Gzyl, G. Heinemeyer, N. Johansson, A. Mutti, J. Schlatter, C. van Leeuwen and P. Verger. 2008. Nitrate in vegetables-scientific opinion of the panel on contaminants in the food chain. EFSA J. 689: 1-79.

AOAC. 2005. Official Methods of Analysis of AOAC International. AOAC International, Gaithersburg.

Aydinsakir, K., C. Karaca, C. F. Ozkan, N. Dinc, D. Buyuktas and M. Isik. 2019. Excess nitrogen exceeds the European standards in lettuce grown under greenhouse conditions. Agron. J. 111: 1-6.

Bahadoran, Z., P. Mirmiran, S. Jeddi, F. Azizi, A. Ghasemi and F. Hadaegh. 2016. Nitrate and nitrite content of vegetables, fruits, grains, legumes, dairy products, meats and processed meats. J. Food Compos. Anal. 51: 93-105.

Bian, Z., R. Cheng, Y. Wang, Q. Yang and C. Lu. 2018. Effect of green light on nitrate reduction and edible quality of hydroponically grown lettuce (Lactuca sativa L.) under short-term continuous light from red and blue light-emitting diodes. Environ. Exp. Bot. 153: 63-71.

Bóbics, R., D. Krüzselyi and J. Vetter. 2016. Nitrate content in a collection of higher mushrooms. J. Sci. Food Agric. 96: 430-436.

Bruning-Fann, C. S. and J. B. Kaneene. 1993. The effects of nitrate, nitrite and $\mathrm{N}$-nitroso compounds on human health: A review. Vet.
Hum. Toxicol. 35: 521-538.

Cardenas-Navarro, R., S. Adamowicz and P. Robin. 1999. Nitrate accumulation in plants: A role for water. J. Exp. Bot. 50: 613-624.

Chan, T. Y. K. 2011. Vegetable-borne nitrate and nitrite and the risk of methaemoglobinaemia. Toxicol. Lett. 200(1-2): 107-108.

Colla, G., H. J. Kim, M. C. Kyriacou and Y. Rouphael. 2018. Nitrate in fruits and vegetables. Sci. Hortic. 237: 221-238.

Correia, M., A. Barroso, M. F. Barroso, D. Soares, M. B. P. Oliveira and C. Delerue-Matos. 2010. Contribution of different vegetable types to exogenous nitrate and nitrite exposure. Food Chem. 120: 960-966.

Della, B. F., L. Vitali, R. Fett and A. C. O. Costa. 2014. Development and validation of a sub-minute capillary zone electrophoresis method for determination of nitrate and nitrite in baby foods. Talanta. 122: 23-29.

Ekart, K., A. Hmelak Gorenjal, E. Madorran, S. Lapajne and T. Langerholc. 2013. Study on the influence of food processing on nitrate levels in vegetables. EFSA Support. Publ. 10: 1-10.

European Commission. 2011. Commission regulation (EU) No 1258/2011 of 2 December 2011 amending regulation (EC) No 1881/2006 as regards maximum levels for nitrates in foodstuffs. O. J. Euro Union. 320: 15-17.

Favaro-Trindade, C. S., L. S. Martello, R. R. Petrus and J.B.S. Ferraz. 2007. Effect of the organic, hydroponic and conventional cultivation systems on smooth lettuce quality. Braz. J. Food Technol. 10: 111-115.

Guadagnin, S. G., S. Rath and F.G.R. Reyes. 2005. Evaluation of the nitrate content in leaf vegetables produced through different agricultural systems. Food Addit. Contam. 22: 1203-1208.

Habermeyer, M., A. Roth, S. Guth, P. Diel, K. H. Engel, B. Epe, P. Fürst, V. Heinz, H. U. Humpf, H. G. Joost, D. Knorr, T. Kok, S. Kulling, A. Lampen, D. Marko, G. Rechkemmer, I. Rietjens, R. H. Stadler, S. Vieths, R. Vogel, P. Steinberg and G. Eisenbrand. 2015. Nitrate and nitrite in the diet: How to assess their benefit and risk for human health. Mol. Nutr. Food Res. 59: 106-128.

Haftbaradaran, S., A. H. Khoshgoftarmanesh and M. J. Malakouti. 2018. Assessment, mapping, and management of health risk from nitrate accumulation in onion for Iranian population. Ecotoxicol. Environ. Saf. 161: 777-784.

lammarino, M., A. Di Taranto and M. Cristino. 2013. Endogenous levels of nitrites and nitrates in wide consumption foodstuffs: Results of five years of official controls and monitoring. Food Chem. 140: 763-771.

Jonvik, K. L., J. Nyakayiru, P. J. Pinckaers, J. M. Senden, L. J. van Loon and L. B. Verdijk. 2016. Nitrate-rich vegetables increase plasma nitrate and nitrite concentrations and lower blood pressure in healthy adults. J. Nutr. 146: 986-993.

Kyriacou, M. C., G. A. Soteriou, G. Colla and Y. Rouphael. 2019. The occurrence of nitrate and nitrite in Mediterranean fresh salad vegetables and its modulation by preharvest practices and postharvest conditions. Food Chem. 285: 468-477.

Kreutz, D. H., M. Weizenmann, M. J. Maciel and C.F.V. de Souza. 2012. Nitrate and nitrite determination in vegetables produced in conventional and organic farming in the region of taquari valley RS. J. Health Sci. 14: 105-110.

Lei, B., Z. Bian, Q. Yang, J. Wang, R. Cheng, K. Li, W. Liu, Y. Zhang, $\mathrm{H}$. Fang and Y. Tong. 2018. The positive function of selenium supplementation on reducing nitrate accumulation in hydroponic lettuce (Lactuca sativa L.). J. Integr. Agric. 17: 837-846.

Lima, J. D., S. Moraes, S. Helena, M. Gorla, F. N. Ibrahim and A. Carlos. 2008. Acúmulo de compostos nitrogenados e atividade 
da redutase do nitrato em alface produzida sob diferentes sistemas de cultivo. Pesqui. Agropecu. Trop. 38: 180-187.

Santamaria, P. 2006. Nitrate in vegetables: Toxicity, content, intake and EC regulation. J. Sci. Food Agric. 86: 10-17.

Stavroulakis, G., D. Kafouris, M. Christofidou, L. Paikousis, E. Christou, M. Christodoulidou, P. Kanari and E. IoannouKakouri. 2018. Occurrence of nitrate in vegetables and dietary exposure assessment for the Cypriot adolescent consumers. Accredit. Qual. Assur. 23: 115-122.

Stertz, S. C., P. T. P. Penteado and R. J. S. de Freitas. 2004. Nitrites and nitrates in horticultures produced by the conventional, organic and hydroponic cultivation systems in the metropolitan region of Curitiba. Rev. Inst. Adolfo Lutz. 63: 200-207.

Suresh, G., W. Xiong, T. Rouissi and S. K. Brar. 2018. Nitrates. In: Reference Module in Food Science. Academic Press, Cambridge, pp. 196-201.

Weitzberg, E. and J. O. Lundberg. 2013. Novel aspects of dietary nitrate and human health. Annu. Rev. Nutr. 33: 129-159.

World Healthy Organization. (2003). Diet, Nutrition and the Prevention of Chronic Diseases: Report of a Joint WHO/FAO Expert Consultation. WHO Technical Report Series, No. 916. World Healthy Organization, Geneva, Switzerland. 